\title{
AWARENESS ABOUT MEDIATION AS AN ALTERNATIVE FORM OF DISPUTE RESOLUTION: PRACTICES IN THE REPUBLIC OF MACEDONIA
}

Dr. Aleksandra Stoilkovska, Faculty of Human Resources Management, University of Tourism and Management in Skopje, Republic of Macedonia, E-mail: a.stoilkovska@utms.edu.mk

Dr. Valentina Mucunska Palevski, Faculty of Public Relations, University of Tourism and Management in Skopje, Republic of Macedonia, E-mail: v.p.mucunska@utms.edu.mk

Dr. Jana Ilieva, Faculty of Human Resources Management, University of Tourism and Management in Skopje, Republic of Macedonia, E-mail: j.ilieva@utms.edu.mk

Received: March, 23.2015.

Accepted: May, 05.2015.

Original Article

UDK 347.965.42(497.7)

\begin{abstract}
Disputes resolved with the use of mediation as a form of dispute resolution are rare (or at striking level) in the practice in our country. In order to increase the number of disputes that were successfully completed based on mediation, it is necessary for the people to know about the alternative forms of resolving litigation. The lack of information contributes to the lack of trust in any resolution of the dispute except in the court. There is also the positive practice of resolving disputes through mediation macular placed in public. This Paper treats the action research which aims to connect the people awareness of mediation as a form of negotiation through which can quickly and easily, without major financial implications, to resolve any dispute. This paper is based on a survey with the members of Chamber of Mediators of the Republic of Macedonia. These results clearly confirm the lack of information among the local population about the forms of dispute resolution that are available and the benefits they offer.

Keywords: Negotiation, Mediation, Information, Litigation, Public.
\end{abstract}

\section{INTRODUCTION}

Global Information Society affirms the need to constantly monitor the latest innovative trends in all areas, especially in those who are important to promote and facilitate the business and administrative processes. Following the latest methods of dispute resolution available to modern society, in the Republic of

\footnotetext{
Corresponding Author

Dr. Jana Ilieva, Faculty of Human Resources Management, University of Tourism and Management in Skopje, Republic of Macedonia E-mail: j.ilieva@utms.edu.mk
}

Macedonia the mediation is promoted as an alternative tool for solving problems and disputes, without major financial implications. The first Law on Mediation in the Republic of Macedonia, (Official Gazette of the Republic of Macedonia No. 60/2006) that was adopted in 2006 has been prepared in accordance with the strategy and the commitment of the Republic of Macedonia to be integrated into the European mainstream, taking into account the numerous recommendations of the Council of Europe, the area of the mediation, addressed to the Member States to improve the efficiency of the judicial system and trial within a reasonable time, which provides a more cost effective, faster and more effective, to which the parties have easy access, and thereby ensure confidentiality, neutrality and impartiality.

However, this law, like all his further changes that resulted in the adoption of the new Law on Mediation (Official Gazette of the Republic of Macedonia No. 188/2013, did not achieve the expected effects, such as: fast and economical resolution of disputes in order to realize the common interests of the parties. Hence, the relevance of the phenomenon that is being investigated is related to inefficiency in resolving litigation in the Republic of Macedonia and low quality of adopted judicial decisions. The problem occurs in the segment of the lack of public awareness about the possibility of resolving disputes using mediation which eliminates initiation of the trial. That means you need to create mechanisms in which jurisprudence opposing sides will initially be directed to resolve the dispute using 
mediation. If mediation fails then the resolution of the dispute will be decided in the court. The lack of information is not only a problem for the countries included in the negotiation process but also for the court administration. The basic strategy in mediation is the negotiation between two opposing sides through a neutral observer/ mediator who has facilitation, encouraging and creating win-win outcome role in the process.

In this context, the article will focus on the need for promotion of mediation as a new paradigm in the cognitive process of resolving problems and conflicts. There entails a necessity of creation and promotion of new mental code to the public, which will encourage stakeholders to use this effective mechanism. Therein, of particular importance is the proactive role of the Chamber of Mediators as a leader in these processes, and, at the same time, the anticipation of its principles of responsibility. Finally, the mediator, as a central figure in the process, with his credibility and expertise shall become a synonym for recognizing mediation as an efficient, effective and operative remedy, and thus give more visibility to the mediation.

\section{MEDIATION}

Mediation is a voluntary, informal and flexible process of dispute resolution. It is a form of dispute resolution, found outside the adjudicative space of the courtroom or tribunal, where parties in dispute or conflict utilities the assistance of a third-party neutral to attempt to resolve their dispute (Spencer, Brogan and Brogan, 2006). The role of the mediator is to guide the conflicting parties to find a solution partnership through focus meetings that clearly define the problem and issues of stakeholders, establishing effective communication, creating an atmosphere of understanding and acceptance of the other position and generating innovative solutions by defining the alternatives for a solution acceptable to both sides. Using both, knowledge and resources, the mediator proposes solutions that become the subject of further negotiation when the agents in conflict cannot solve the dispute by themselves, (Trescak, Sierra and Simoff, 2014).

The mediator encourages parties to communicate, to be collaborative while trying to resolve the problem. They don't make decisions for the parties, (Crawley and Graham, 2002). Some sources point to the need of neutrality of the mediator and decision-making only on the basis of objective truth, (Rothman, 2014). In order for the stakeholders to feel safe in the process of negotiation, the mediator should establish mutually agreed rules i.e. a protocol. There are different approaches to what are the common stages of the process of mediation. Among the most acceptable and universal determination is the Marian Roberts five-stage process (Roberts, 2008):

Stage I: Establish the arena - The first joint session

Stage II: Define and clarify the issues The separate interviews

Stage III: Explore the issues - Return to the joint meeting

Stage IV: Development of options

Stage V: Securing agreement

The mediator is a person who performs the procedure for mediation, according to the principles of mediation. The mediation procedure is a specific type of procedure which by its nature is a voluntary, efficient, effective and financially affordable, (Riskin, 1994). Mediation is private, confidential and informal. The process of mediation is less adversarial than litigation or arbitration.

\section{PROMOTING MEDIATION}

Mediation includes different approaches to conflictresolution. Most efficientapproaches are negotiation and facilitation. The promotion of mediation in public includes the application of powerful promotional strategies and tactics that allow placement of information to the public through the media, events, and discussion groups. Strategic promoting mediation informs the public with a set of tools for proactively management of the problems, conflicts, and disputes in the business community and public administration. The purpose of the promotional activities is to sensitize the community about the need for a change in the mental code by creating new social, societal and business competencies based on an effective communication, partnership, respect for diversity and creative dispute resolution.

In the dispute resolution, negative emotions such as angriness, enthusiasm, excitation, guilt and remorse represent important obstacles that can be connected and mixed, (Posthuma, 2012). The mediator must know how to manage the emotions of the both sides in order to finish the dispute with satisfaction among the involved parties. Also, the 
mediator must know how to bridge the past that creates problems by mediating in future tense, (Haynes, Gretchen Fong, Haynes and Fong, 2012).

The Past and Future in Mediation (same, 7)

$\begin{array}{ll}\text { Past } & \text { Future } \\ \text { Problem } & \text { Solution } \\ \text { Complaints } & \text { Goals } \\ \text { Sameness } & \text { Difference } \\ \text { Unchangeable } & \text { Change } \\ \text { Hopeless } & \text { Hopeful } \\ \text { Do Not Want } & \text { Do Want } \\ \text { Cannot Work } & \text { Can Work } \\ \text { Stuck } & \text { Fluid } \\ \text { Resistance } & \text { Openness }\end{array}$

Effective mediation produces two new paradigms: acceptance of the situation of the opposing party and individual change in dealing with the problems. Mediation can transform conflicts' and disputes' destructive force in a positive and constructive interaction, which can reflect the entire business community.

\section{CURRENT SITUATION IN THE REPUBLIC OF MACEDONIA}

The currency of mediation as an alternative dispute resolution is related to the use of an integrated approach to effective conflict resolution. From a legal perspective, the efficiency in resolving disputes requires a relevant procedure. As a result of the ongoing need for mediators, the Ministry of Justice created the Macedonian Chamber of Mediators, going through the process of training, and then taking the exam to get a license for a mediator. The public in our country is not sufficiently informed about the benefits of public mediation, which means that there is no communication strategy of the Chamber of Mediators and other relevant institutions to promote mediation. In certain business areas and categories, there is resistance to mediation as a result of insufficient information. The transparency of the activities of all parties involved and responsible for the development of mediation is low.

There is no website for mediation, with the exception of the main legal acts which are published on the website of the Ministry of Justice. In this context, taking into account the legislative practices of developed economies in the world, the Republic of Macedonia acceded to certain activities that are still at the initial exercise. The efforts of the Republic of Macedonia are getting closer to current European legislation which initiated the processes and activities for the implementation and institutionalization of mediation. Relevance to the emergence of the study identifies the problem of research that affirms the need of constant promotion, implementation and institutionalization of the mediation as a modern alternative tool for dispute resolution.

\section{RESEARCH}

After determining the problem and the purpose of the survey, a general hypothesis is created. It reads: awareness about mediation as an alternative tool contributes to the efficient resolution of disputes. The survey was conducted by questionnaire to obtain all relevant information about the level of awareness of the entities that are directly or indirectly involved in mediation to determine the views and opinions of the mediators of the Directory of Mediators of the Ministry of Justice to analyze the elements and characteristics of mediation and dispute resolution and mediation to determine which activities should be initiated to encourage the use of mediation in resolving disputes. The research was conducted with an online survey on a representative sample, of 82 licensed members of the Chamber of Mediators of the Republic of Macedonia. The purpose of this survey is to evaluate the impact of the information awareness of the parties in the dispute over the success of mediation. The research was conducted in July 2014. The questionnaire was sent by e-mail to the licensed mediators and it was composed of 22 questions.

\subsection{Results of the survey}

The analysis of the survey gave results in addition to proving of the set hypotheses. Issues (standings) are related exclusively to the situation in the Republic of Macedonia. Below are presented some of the issues that have key importance for obtaining of conclusions of the survey. The clause "The mediation is maintained method in dispute resolution in the Republic of Macedonia", which was referred to as the first question in the questionnaire, most of the respondents, 47 
respondents (55\%) have responded: I do not agree that mediation in solving issues is sufficiently maintained. In thatdirection 13 respondents answered: I do not agree at all (15\%) versus 0 answers $(0 \%)$ : I completely agree and 10 responses $(12 \%)$ : I agree. Fairly agree 12 respondents or $15 \%$ of them. These results speak for the low representation of mediation in resolving disputes in the Republic of Macedonia. Given the fact that the participants were people who are actively involved in the use of mediation in the settlement of disputes, it is clear that the relevance of the data is high. These results are in favor of the assumption that mediation is a very little bluntly form of dispute resolution.

Table 1. Table of obtained answers to question number 1

\begin{tabular}{lcc}
\hline Answer & Respondents & Percentage \\
\hline I completely agree & 0 & 0 \\
\hline I agree & 10 & $12 \%$ \\
\hline I fairly agree & 12 & $15 \%$ \\
\hline I do not agree & 47 & $57 \%$ \\
\hline I do not agree at all & 13 & $16 \%$ \\
\hline Total & 82 & $100 \%$ \\
\hline
\end{tabular}

Table number 1 presents the results of question number 1 .

The third question "There is a need for media campaign which will aim to convey the message of the benefits offered by the mediation" most respondents, 35 or $43 \%$ agree that a media campaign is required that will aim to convey the message of the benefits offered by the mediation. In addition to that answer, 27 respondents or $33 \%$ completely agree. $21 \%$ or 17 respondents fairly agree, and only three or $3 \%$ do not agree with that. The total percentage of agreement with this statement is even $74 \%$.It is a high score indicator which indicates the need for a media campaign that will allow the public to be informed of the advantages offered by mediation.

Table 2. Table of obtained answer to question number 3

\begin{tabular}{lcc}
\hline Answer & Respondents & Percentage \\
\hline I completely agree & 27 & $33 \%$ \\
\hline I agree & 35 & $43 \%$ \\
\hline I fairly agree & 17 & $21 \%$ \\
\hline I do not agree & 3 & $3 \%$ \\
\hline I do not agree at all & 0 & $0 \%$ \\
\hline Total & 82 & $100 \%$ \\
\hline
\end{tabular}

Table number 2 presents the results of question number 3 .

The fourth question resulted from the assumption of a small commitment of the Chamber of mediators in the process of informing the public or the individuals which are their potential clients. It reads: "Informing citizens about mediation will increase if the engagement of the Chamber of Mediators increases." In addition the following results were obtained: huge $43 \%$ or 35 respondents fairly agree with the conclusion, $38 \%$ or 31 respondents agreed, 9\% of respondents completely agree, while only $1 \%$ or 1 respondent did not agree that the awareness of citizens for the mediation will increase if the engagement of the Chamber of Mediators increases. In this statement the neutral position and the percentages of disagreement indicates that the Chamber of mediators should and must have its proper role in increasing the awareness of citizens for mediation. This fact suggests that the Chamber of Mediators has a passive role in increasing the awareness of citizens.

Table 3. Table of received answers to question number 4

\begin{tabular}{lcc}
\hline Answer & Respondents & Percentage \\
\hline I completely agree & 9 & $11 \%$ \\
\hline I agree & 31 & $38 \%$ \\
\hline I fairly agree & 35 & $43 \%$ \\
\hline I do not agree & 6 & $7 \%$ \\
\hline I do not agree at all & 1 & $1 \%$ \\
\hline Total & 82 & $100 \%$ \\
\hline
\end{tabular}

Table number 3 presents the results of question number 4 .

After the confirmation of the low application of mediation in the state, there is a need for assessment by the mediators of the level of public awareness about mediation. Therefore, the sixth question is: "How do you grade the level of awareness for mediation in the Republic of Macedonia". The largest number of respondents mediators, 66 or $80 \%$, rated the level of awareness for mediation in the country as low, 9 of them or $11 \%$ rated it as medium, and 7 or $9 \%$ rated it as high. This ranking of information by respondents with high $80 \%$ that responded "low" indicates that it is a great lack of information to the public. It points to the need to use a variety of instruments that will increase the awareness of the citizens for mediation, in general, its advantages and benefits.

Table 4. Table of received answers to question number 6

\begin{tabular}{lcc}
\hline Answer & Respondents & Percentage \\
\hline High & 7 & $9 \%$ \\
\hline Medium & 9 & $11 \%$ \\
\hline Low & 66 & $80 \%$ \\
\hline Total & 82 & $100 \%$ \\
\hline
\end{tabular}


Table number 4 presents the results about the level of awareness of mediation of citizens.

The fifteenth question aims to measure the impact of awareness of customer competence of the mediator for the successful resolution of negotiations. It reads: "The information about the neutrality of the mediator positively affects the decision about the acceptance of mediation". $44 \%$ or 36 of respondents agree that the decision to initiate mediation affects the awareness of client competencies. The mediator must have highly developed negotiation skills to be able to properly direct the discussion towards the solution of the dispute, $32 \%$ or 26 respondents completely agree, $13 \%$ or 11 respondents fairly agree, and $11 \%$ or 9 respondents disagree with the statement. The results confirm the thesis that if the involved parties are informed about the place and the role of the mediator in the process of dispute resolution, i.e. they are informed about the neutrality of the mediator in the whole process of mediation, then the clients will easily make the choice on mediation as an alternative form of dispute resolution.

Table 5. Table of received answers to question number 15

\begin{tabular}{lcc}
\hline Answer & Respondents & Percentage \\
\hline I completely agree & 26 & $32 \%$ \\
\hline I agree & 36 & $44 \%$ \\
\hline I fairly agree & 11 & $13 \%$ \\
\hline I do not agree & 9 & $11 \%$ \\
\hline I do not agree at all & 0 & $0 \%$ \\
\hline Total & 82 & $100 \%$ \\
\hline
\end{tabular}

Table number 5 presents the results of question number 15 .

The informed clients about the neutrality and objectivity of the mediator can be a very strong factor for gaining the trust of the involved parties in the relevance of the mediation as a form of dispute resolution. Based on the negotiating skills, the mediator may acquire confidence among stakeholders in the relevance of mediation as a form of dispute resolution. The statement that "trust can help in resolving the dispute" is explored through the question: "If the information about the neutrality of the mediator positively influences the stakeholders to achieve a higher level of confidence among them, and will contribute to facilitating resolution of dispute." The obtained results in large percentage confirm the connection of achieved confidence with the positive resolution of the dispute. Only 45 respondents or $55 \%$ of the mediators agree with it, 17 respondents or $21 \%$ of mediators completely agree and 8 respondents or $10 \%$ fairly agree. In contrast, 12 respondents or $14 \%$ disagree, and $0 \%$ doesn't agree with the statement that achieving trust among stakeholders can facilitate a solution of the dispute. Achieving a high level of confidence actually allows mediation to take place in a more relaxed atmosphere where easily achieved contract dispute is more likely to happen.

Table 6. Table of received answers to question number 16

\begin{tabular}{lcc}
\hline Answer & Respondents & Percentage \\
\hline I completely agree & 17 & $21 \%$ \\
\hline I agree & 45 & $55 \%$ \\
\hline I fairly agree & 8 & $10 \%$ \\
\hline I do not agree & 12 & $14 \%$ \\
\hline I do not agree at all & 0 & $0 \%$ \\
\hline Total & 82 & $100 \%$ \\
\hline
\end{tabular}

The previous table number 6 shows the results gained from the respondents in the context of the relation of gained trust by the involved parties and the process of mediation toward successful dispute resolution.

The question "What activities do you think should be taken to raise awareness of citizens about mediation and their confidence in it" the largest number of respondents $52 \%$ felt they needed a media campaign, $20 \%$ needed institutional support for mediation, $16 \%$ required benefits from mediation in time and finances, and $12 \%$ highlighted the positive examples solved by mediation solution. None of the respondents $0 \%$ agree that there is a need of mediation workshops as an activity that should be taken into account in order to raise the information of the citizens about mediation.

This question, as well as the third one, presented above, only confirm the need of media campaign. The respondents had the opportunity to choose between other activities in order to raise the information of the citizens about mediation. The answers to this question with the high percentage, show the need of positive examples of mediation in practice which confirmed that the stakeholders have financial benefits. Also, this institutional support of mediation is valued as important, and thus is a confirmation of the necessity of advanced involvement of the Chamber of mediators in the process of citizen information. 
Table 7. Table of received answers to question

\begin{tabular}{lcc}
\hline Answers & Respondents & Percentage \\
\hline Media campaign & 43 & $52 \%$ \\
\hline Media workshop & 0 & $0 \%$ \\
\hline Highlighting positive examples & 10 & $12 \%$ \\
\hline Benefits of mediation in time and finances & 13 & $16 \%$ \\
\hline Institutional support & 16 & $20 \%$ \\
\hline Total & 82 & $100 \%$ \\
\hline
\end{tabular}

Table number 7 shows the results of the respondents about the question in the context of the location of the necessity activities for increased process of citizen information about mediation.

The question number 20 "In your opinion, what is important for successful mediation", for $39.02 \%$ of the mediators the most important thing are the skill of the mediator, for $24.39 \%$ the good negotiating is important to come to a solution to the dispute, for $13.41 \%$ it is the knowledge of citizens and financial costs, and only $9.76 \%$ think that the most important thing is the speed of finding a solution out of the court. This indicates that a successful mediation requires the mediator to have good negotiation skills and the ability for mediation to be successful. This only justifies the obligation to license the future mediators provided by the Law of Mediation.

Table 8. Table of received answers to question

\begin{tabular}{lcc}
\hline Answer & Respondents & Percentage \\
\hline Knowledge of citizens & 11 & $14 \%$ \\
\hline Mediator's skills & 32 & $39 \%$ \\
\hline Negotiation as a skill & 20 & $24 \%$ \\
\hline Seed of finding a solution out of court & 8 & $10 \%$ \\
\hline Financial costs & 11 & $13 \%$ \\
\hline Total & 82 & $100 \%$ \\
\hline
\end{tabular}

Table number 8 shows the results obtained from the respondents on question number 20.

\section{CONCLUSIONS}

The current conditions of the implementations of mediation as an alternative form of dispute resolution show that in the Republic of Macedonia the mediation is used rarely. In the context of finding the causes of this situation, the impact of public awareness about the benefits of mediation has been explored. As participants in the survey were used members of the Chamber of Mediators. The findings resulting from the following:

- Informing the public about the benefits that citizens have when they use mediation as an alternative form of dispute resolution has a great impact on the decision this way of resolving disputes to be applied.

- A media campaign is needed to inform citizens about mediation.

- Informing the stakeholders with neutrality and impartiality of the mediator in the mediation process allows increasing confidence of the individual to the mediator and glad acceptance of mediation as the useful process. Thus, stakeholders are likely to accept cooperation with the mediator which in turn facilitates the whole process easier and leads to resolution of the dispute.

- Through various forms, it is needed to inform the public about mediation, financial benefits and benefits in speed of dispute resolution.

- The increase in awareness is necessary to actively involve the Chamber of mediators of the Republic of Macedonia. The unresponsiveness which currently is present, that is inappropriate to the current needs of the country.

- The public should be informed about the competences of the mediators that must be on a very high level. Knowing the negotiating skills must be part of the remit of the mediator, and that (to) ensure that the license held by each of them.

The conducted research was conceptualized so that respondents gave guidelines for increasing mediation as an alternative to resolving disputes. That is how the recommendation for greater institutional coverage support mediation emerged.

\section{Conflict of interests}

Authors declare no conflict of interest.

\section{REFERENCES}

Corpus of State Regulative on Mediation, Ministry of Justice of the Republic of Macedonia, Retrieved from http://www.pravda.gov.mk/ resursi.asp?lang $=$ mak\&id=11

Crawley, J., Graham, K. (2002). Mediation for Managers: Resolving Conflict and Rebuilding Relationships at Work. Nicholas Brealey Publishing, London.

Haynes, J. M., Haynes, J. M. H. G. L., Fong, L. S., \& Haynes, G. L. (2012). Mediation: Positive conflict management. Suny Press.

Posthuma, R. A. (2012). Conflict management and emotions. International Journal of Conflict Management, 23(1), 4-5. 
Riskin, L. L. (1994). Mediator orientations, strategies and techniques. Alternatives to the High Cost of Litigation, 12(9), 111-114.

Roberts, M. M. (2008). Mediation in family disputes: Principles of practice. Ashgate Publishing, Ltd.

Rothman, J. (2014). The reflexive mediator. Negotiation Journal, 30(4), 441-453.

Spencer, D., \& Brogan, M. (2006). Mediation law and practice. Cambridge University Press.

Trescak, T., Sierra, C., Simoff, S., \& de Mantaras, R. L. (2014). Dispute Resolution Using Argumentation-Based Mediation. arXiv preprint arXiv:1409.4164. Retrieved from http://arxiv. org/pdf/1409.4164v1.pdf

Whatling, T. (2012). Mediation Skills and Strategies: A Practical Guide. Jessica Kingsley Publishers.

Закон за медијација. (2006). Службен весник на Р. Македонија бр. 60/06

Закон за медијација. (2013). Службен весник на P. Македонија бр. 188/13 
(IJCRSEE) International Journal of Cognitive Research in Science, Engineering and Education Vol. 3, No.1, 2015. 